\title{
Retrieving Soil Moisture in Hebei by Using Temperature Vegetation Dryness Index
}

\author{
Fei Mao, Lei Han \\ Meteorological Technology and Equipment Center in Hebei Province, Shijiazhuang, China \\ Email: ct296394134@163.com
}

How to cite this paper: Mao, F. and Han, L. (2017) Retrieving Soil Moisture in HeBei by Using Temperature Vegetation Dryness Index. Journal of Geoscience and Environment Protection, 5, 10-16. https://doi.org/10.4236/gep.2017.58002

Received: March 20, 2017

Accepted: July 18, 2017

Published: July 21, 2017

Copyright @ 2017 by authors and Scientific Research Publishing Inc. This work is licensed under the Creative Commons Attribution International License (CC BY 4.0).

http://creativecommons.org/licenses/by/4.0/

\section{(c) (i) Open Access}

\begin{abstract}
The temperature-vegetation index space coupled with information of surface temperature and vegetation, is an important method to realize soil moisture estimation and agricultural drought monitoring. In order to estimate the soil moisture in the study area, we collected soil relative humidity of Agricultural meteorological station and downloaded Moderate Resolution Imaging Spectrometer (MODIS) image data. Then, the temperature vegetation dryness index was calculated based on the MODIS Normalized difference vegetation index (NDVI) and land surface temperature (LST). A correlation analysis of TVDI and soil relative humidity at depth of $10 \mathrm{~cm}$ was carried out and an empirical model of moisture estimation was established. Finally, another set of data was used to validate the accuracy of model. The results show that the TVDI method can be used to achieve the soil moisture in the study area. The empirical model has certain universality in the study area, and obtains a high accuracy of soil moisture estimation with an $\mathrm{R}^{2}$ of 0.374 and RMSE of $11.73 \%$.
\end{abstract}

\section{Keywords}

Remote Sensing, Inversion, Temperature Vegetation Dryness Index

\section{Introduction}

Soil moisture is a physical quantity indicating the degree of soil dryness and wetness in a certain depth soil layer which it is an important index for monitoring the degree of soil drought. It is also an important basic parameter in the fields of hydrology, meteorology and agricultural science [1]. Compared with the traditional soil moisture monitoring method, the soil moisture remote sensing technology has the characteristics of high timeliness and wide monitoring range, which provides an effective means for the regional soil moisture information 
acquisition [2].

The model obtained by using the vegetation index and surface temperature to construct the feature space, which integrates the physiological and ecological significance of the two parameters, can be used to estimate the surface soil moisture [3]. Commonly used exponential models include water deficit index (WDI), vegetation water supply index (VSWI), temperature vegetation dryness index (TVDI) and so on. These models have been applied in the retrieval of soil moisture, among which the TVDI method is the most widely used. Based on the NOAA/AVHRR data and the LST-NDVI feature space, Qi Shuhua constructs the TVDI index and realized the monitoring of the national drought [4]. Yao Chunsheng uses MODIS product data to construct LST-NDVI feature space, and calculate the TVDI index as soil moisture monitoring indicators to achieve the Xinjiang region soil moisture inversion [5]. Using MODIS surface temperature and enhanced vegetation index, Yanfeng analyzes and evaluates the ability of TVDI index to estimate the soil water status at $10 \mathrm{~cm}, 20 \mathrm{~cm}$ and $50 \mathrm{~cm}$ depth [6]. The results show that the method of surface soil moisture retrieval is better than using characteristic space method.

In order to realize the regional drought monitoring in Hebei province which has a high occurrence frequency of agricultural drought, considering the characteristics of the underlying surface, the feasibility of the remote sensing data source and the research method. This paper takes MODIS data as the remote sensing data source to study the drought monitoring method in Hebei province with TVDI index. Firstly, the MODIS surface reflectivity data are used to calculate the NDVI index. Based on the NDVI and LST data of each period, the temperature vegetation index feature space is constructed, and the wet and dry edges of the feature space are fitted to calculate the TVDI index. Furthermore, by fitting the relationship between measured soil moisture data and TVDI index, a soil moisture inversion model was established, and the accuracy of the above model was validated and evaluated by using another set of soil moisture data. In this paper, an effective monitoring method for regional agricultural drought monitoring is provided by constructing a soil moisture inversion model. Through the effective monitoring of serious arid areas, the government guides the relevant departments in a timely manner to take artificial irrigation measures to inhibit the development of drought. This can, to a certain extent, reduce the agricultural losses caused by drought.

\section{Data and Methods}

\subsection{Study Area and Data Set}

\subsubsection{Summary of the Study Area}

Hebei Province is located in the North China Plain $\left(113^{\circ} 11^{\prime} \mathrm{E}-119^{\circ} 45^{\prime} \mathrm{E}\right.$, $\left.36^{\circ} 05^{\prime} \mathrm{N}-42^{\circ} 37^{\prime} \mathrm{N}\right)$. The climate type is temperate monsoon climate, the precipitation in summer is the most and the winter is the least. In recent years, with the impact of climate change, frequent occurrence of drought on agricultural pro- 
duction has seriously affected, so the development of soil moisture monitoring in Hebei Province has become particularly important, confirm that you have the correct template for your paper size. This template has been tailored for output on the custom paper size $(21 \mathrm{~cm} * 28.5 \mathrm{~cm})$.

\subsubsection{Data}

In this paper, the original data used for soil moisture inversion include MODIS satellite data and soil relative humidity data of agricultural meteorological station. MODIS is a primary sensor onboard the TERRA and AQUA satellites launched by NASA (National Aeronautics and Space Administration). MODIS data sent by the NASA free to use very convenient access, which has been widely used. The MODIS data used in this paper are the surface reflectivity data and surface temperature data which are less affected by cloud in the study area.

1) Satellite data

Thermal infrared channel data: MOD11A1 is a level-2 data product for daily surface temperature and emissivity data. The surface temperature data used in this work is dated March 28, April 18, 2011 and March 28, Day, April 8, May 8 and 28,2012, a total of six sets of data.

Visible, near infrared channel data: MOD09A1 is a level-3 data product for 8 -day surface reflectance. The data selection date is consistent with the temperature data.

2) Soil relative humidity data of agricultural meteorological station

The data of soil moisture in Hebei Province were downloaded from China Meteorological Science Data Sharing Service Network. The data are measured on the 8th, 18th and 28th of each month based on observations from the Agrometeorological Observatory, with depths of $10 \mathrm{~cm}, 20 \mathrm{~cm}, 50 \mathrm{~cm}, 70 \mathrm{~cm}$ and 100 $\mathrm{cm}$. In this paper $10 \mathrm{~cm}$ relative humidity data was used.

\subsection{Technology}

Temperature Vegetation Dryness Index (TVDI) is the characteristic index of soil moisture. In the study area, if the land surface type covers from bare soil to complete vegetation cover, the soil moisture condition can from drought to extreme humidity, and the scatter plot with the vegetation index and surface temperature data as the horizontal and vertical coordinates is triangular or trapezoidal. A negative correlation in the linear relationship, which is the so-called NDVI-LST feature space. Sandholt [7] studied the NDVI-LST triangular space, and proposed the concept of temperature Vegetation Dryness Index (TVDI). The formula is as follows:

$$
\begin{gathered}
\text { TVDI }=\frac{T s-T s_{\text {min }}}{T s_{\text {max }}-T s_{\text {min }}} \\
T s_{\text {min }}=a_{1}+b_{1} * \mathrm{NDVI} \\
T s_{\text {max }}=a_{2}+b_{2} * \mathrm{NDVI}
\end{gathered}
$$

$T s$ is the surface temperature of any pixel; $T s_{\min }$ is minimum surface tem- 
perature corresponding to the NDVI for a pixel, defined as the wetted edge; $T s_{\max }$ is the maximum surface temperature corresponding to the NDVI for a pixel, defined as a dry edge; $a_{1}, a_{2}, b_{1}, b_{2}$ are the fit coefficients of the dry-edge and wet-side equations, which are obtained by the linear fitting of the dry-wet edge of the LST-NDVI feature space.

\subsection{Fitting Ts-NDVI Feature Space Dry and Wet Edge Equations}

Using the IDL programming language, the LST-NDVI feature space is constructed by using MODIS surface temperature data and vegetation index data. It is very important to select the appropriate pixels in the image for the regression fitting in the process of fitting the wet and dry edges of the feature space. It is assumed that the maximum value of LST decreases with the increase of NDVI, and there is a linear relationship between them. But the truth is that NDVI and LST do not always have a linear relationship. The NDVI value is too high to estimate the vegetation coverage at the early stage of vegetation growth, while the vegetation coverage is too low at the later stage of vegetation growth. The dry and wet edges are extracted when the general limit NDVI between $0.20-0.80$ [8]. Therefore, the maximum and minimum values of the surface temperature corresponding to the NDVI values of each pixel in the study area are extracted by programming. Based on the least squares method, the dry and wet side equations of the LST-NDVI feature space in the study area on march 28th, April 8th, May 5 and 28, 2012 (Table 1) were fitted. The TVDI index of the study area was calculated by using the equation of dry-wet edge and the formula (1). According to the latitude and longitude information of the measured site, the TVDI value can be extracted from the image to analyze the relationship between TVDI and soil moisture. (In Table $1, \mathrm{R}^{2}$ is the correlation coefficient. It is calculated according to the equation).

\section{Results and Analysis}

In order to establish a time-dependent soil moisture inversion model, the relationship between the TVDI index and the measured soil moisture was analyzed. In this paper, the relationship between the TVDI index and the measured soil moisture was analyzed using March 28, April 8, May 8 and 28, the data of soil moisture of Hebei agricultural stations, fitted with TVDI and the relative humidity of $0-10 \mathrm{~cm}$ depth layer (Figure 1 ).

As shown in Figure 1, the relative humidity of the soil was decreased with the

Table 1. Dry and wet edge fitting equation.

\begin{tabular}{ccccc}
\hline & dry edge fitting equation & $\mathrm{R}^{2}$ & wet edge fitting equation & $\mathrm{R}^{2}$ \\
\hline $2012-3-28$ & $y=-33.62 * x+312$ & 0.956 & $y=39.35 * x+265.1$ & 0.899 \\
$2012-4-8$ & $y=-23.45 * x+315.6$ & 0.973 & $y=43.65 * x+265.2$ & 0.943 \\
$2012-5-8$ & $y=-26.08 * x+326.6$ & 0.967 & $y=-0.003 * x+292.4$ & 0.05 \\
$2012-5-28$ & $y=-17.92 * x+324.9$ & 0.943 & $y=-6.228 * x+295.9$ & 0.508 \\
\hline
\end{tabular}


increase of TVDI index. There was a significant negative correlation between TVDI and soil relative humidity, and the correlation coefficient $\mathrm{R}^{2}$ was 0.351 , which reached the significance criterion of 0.01 . In conclusion, the TVDI index can reflect the soil water content in the study area, and the model can be used to invert the soil moisture.

In order to further test the inversion effect of the TVDI index model, a series of data from Hebei Province (March 28 and April 18, 2011) was used to invert the soil moisture. It is important that models were evaluated accurately. Figure 2 is the inversion of the cross-validation with the measured data. From the distribution of the scattered points, most of the points are distributed near the line of $y=x$, which shows that the inversion of the $10 \mathrm{~cm}$ soil moisture and the measured $0-10 \mathrm{~cm}$ soil relative humidity have a good consistency. The correlation coefficient reached 0.374 , and the square root error is $11.73 \%$. The inversion model has a high accuracy of inversion from the correlation coefficient and root mean square error of the inversion results. Obviously, the soil moisture in different areas is different.

The model was used to invert the soil moisture in the study area in 2011, as shown in Figure 3 and Figure 4 (Figure 3 is calculated by model inversion).

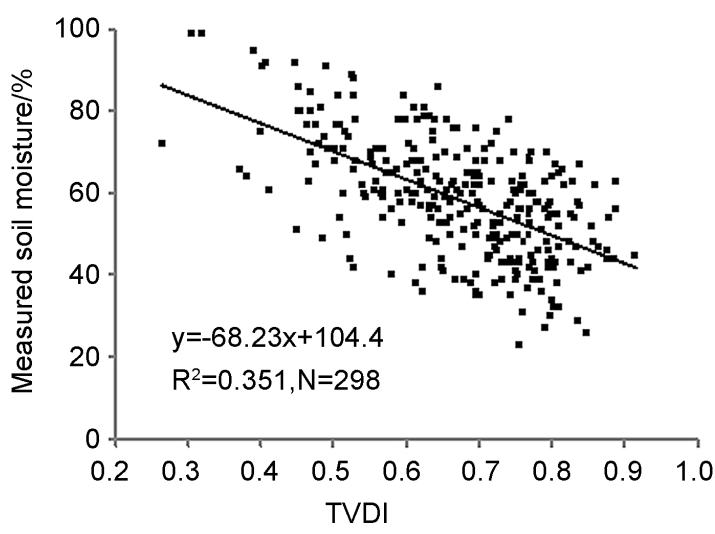

Figure 1. TVDI and measured soil moisture scatter in experimental Area of Hebei province.

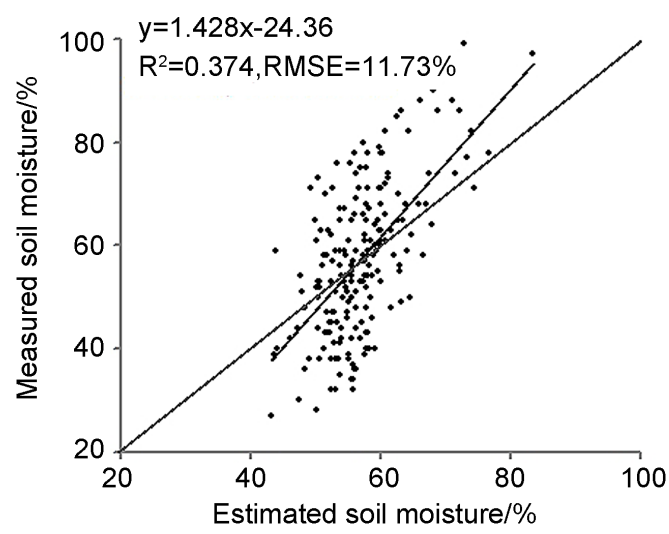

Figure 2. Scatter diagram between measured and estimated soil moisture. 


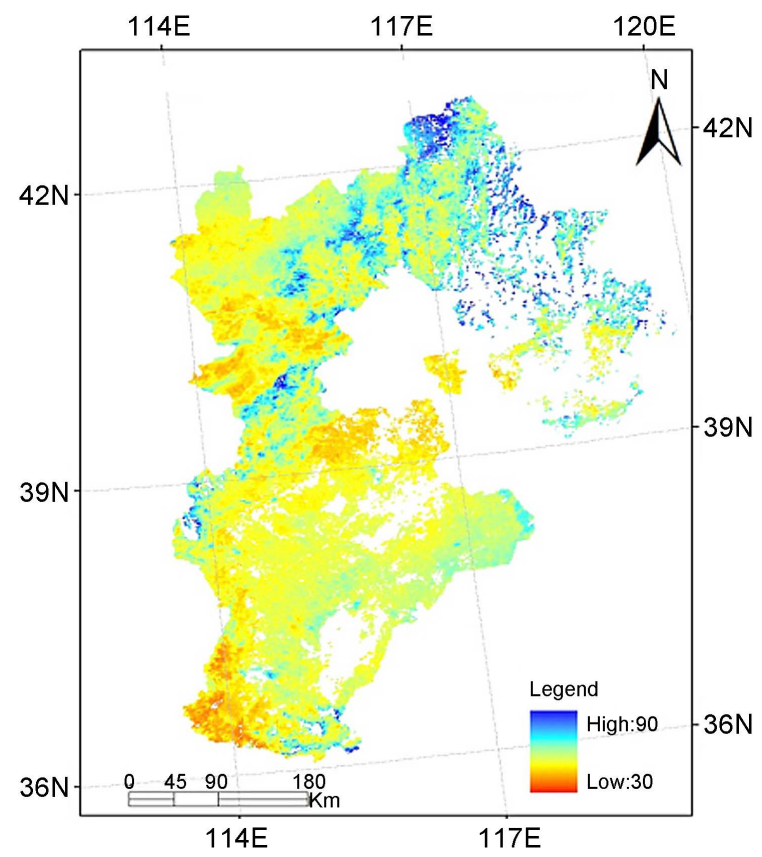

Figure 3. Estimated soil moisture of the study area on March 28, 2011.

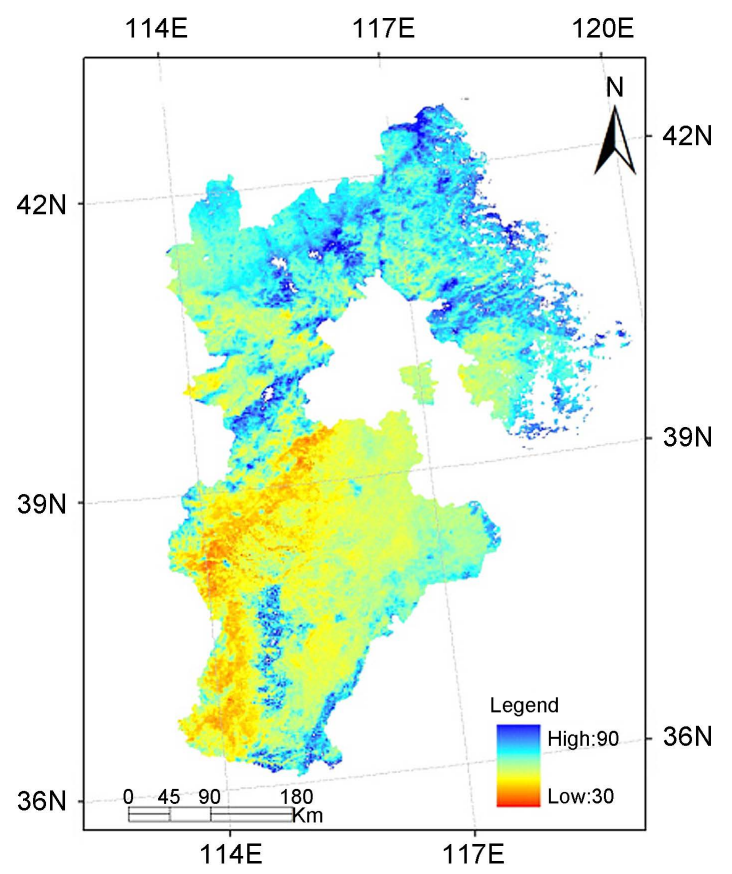

Figure 4. Estimated soil moisture of the study area on April 18, 2011.

\section{Result}

In this paper, the NDVI-LST feature space is constructed using MODIS surface temperature data and surface reflectivity data, and the wet and dry edges of the feature space are fitted to calculate the TVDI index. Based on the TVDI index and measured surface moisture data, a soil moisture inversion model based on 
TVDI index was established, and the soil moisture inversion was realized in $\mathrm{He}-$ bei province.

The main conclusions of the study are as follows: There is a high linear relationship between the TVDI and the measured soil moisture in the study area, and a linear regression model of soil moisture based on TVDI index can be established. Soil Moisture Model Verification Test Surface: $\left(\mathrm{R}^{2}=0.374\right)$ and smaller root mean square error $(\mathrm{RMSE}=11.73 \%)$ of the soil moisture and the measured soil moisture.

The study is based on the data of ground observation and remote sensing images in Hebei province. A generalized soil moisture inversion model was established. The model can be used for soil moisture inversion in Hebei Province. Temperature vegetation dryness index can improve the accuracy of soil moisture detection, so as to construct a reasonable soil water inversion model. This is of great significance for regional drought monitoring and drought prevention.

\section{References}

[1] Jackson, T., Mansfield, K., Saafi, M., et al. (2008) Measuring Soil Temperature and Moisture Using Wireless MEMS Sensors. Measurement, 41, 387-390. https://doi.org/10.1016/j.measurement.2007.02.009

[2] Chen, S., Liu, Y. and Wen, Z. (2012) Satellite Retrieval of Soil Moisture: An Overview. Advances in Earth Science, 27, 1192-1203.

[3] Chen, B., Zhang, X., Hua, K., et al. (2013) Application Study of Temperature Vegetation Drought Index(TVDI) in Grassland Drought Monitoring. Arid Land Geography, 5, 930-937.

[4] Qi, S., Wang, C. and Niu, Z. (2003) Evaluating Soil Moisture Status in China Using the Temperature/Vegetation Dryness Index(TVDI). Journal of Remote Sensing, 5, $420-427+436$.

[5] Yao, C., Zhang, Z. and Wang, X. (2004) Evaluating Soil Moisture Status in XinJiang Using the Temperature Vegetation Dryness Index(TVDI). Remote Sensing Technology and Application, 6, 473-478.

[6] Yan, F. and Wang, Y. (2009) Estimation of Soil Moisture from Ts-EVI Feature Space. Acta Ecologica Sinica, 9, 4884-4891.

[7] Sandholt, Z., Rasmussen, K. and Andersen, J.A. (2002) Simple Interpretation of the Surface Temperature/Vegetation Index Space for Assessment of Surface Moisture Status. Remote Sensing of Environment, 79, 213-224. https://doi.org/10.1016/S0034-4257(01)00274-7

[8] Wang, Z., Liu, C. and Huete, A. (2003) From AVHRR-NDVI to MODIS-EVI: Advances in Vegetation Index Research. Acta Ecologica Sinica, 23, 979-987. 
Submit or recommend next manuscript to SCIRP and we will provide best service for you:

Accepting pre-submission inquiries through Email, Facebook, LinkedIn, Twitter, etc. A wide selection of journals (inclusive of 9 subjects, more than 200 journals)

Providing 24-hour high-quality service

User-friendly online submission system

Fair and swift peer-review system

Efficient typesetting and proofreading procedure

Display of the result of downloads and visits, as well as the number of cited articles Maximum dissemination of your research work

Submit your manuscript at: http://papersubmission.scirp.org/

Or contact gep@scirp.org 